\title{
Antikeratin antibodies in serum and synovial fluid show specificity for rheumatoid arthritis in a study of connective tissue diseases
}

P YOUINOU, ${ }^{1}$ P LE GOFF,${ }^{2}$ C B COLACO,${ }^{3} \mathrm{~J}$ THIVOLET,${ }^{4}$ D TATER,${ }^{4} \mathrm{~J}$ VIAC, ${ }^{4}, \vec{\circ}$ AND M SHIPLEY

From the Departments of ${ }^{1}$ Immunology and ${ }^{2}$ Rheumatology, University Hospital Medical School, Brest, France; the ${ }^{3}$ Department of Rheumatology Research, The Middlesex Hospital, London; and ${ }^{4}$ Unit 209 of INSERM, Lyon, France

SUMMARY Tests for antikeratin antibodies (AKA) were performed on 2152 disease-associated and control sera by indirect immunofluorescence (IF) on rat oesophagus substrate. The incidence of AKA was significantly raised in rheumatoid arthritis $(37 \%)$ in comparison with systemic sclerosis $(8 \%)$, psoriasis $(7 \%)$, ankylosing spondylitis $(6 \%)$, systemic lupus erythematosus $(3 \%), \stackrel{\varrho}{\gtrless}$ and normal controls (2\%). AKA were detected in synovial fluid obtained from patients with $\vec{\bullet}$ rheumatoid arthritis (RA) $(48 \%)$ but not from patients with other conditions. Further ${ }^{\infty}$ experiments on AKA-positive sera showed reactivity with stratum corneum of rabbit prepuce and lips. A specific rabbit antihuman keratin antiserum was shown, by IF and inhibition studies, to have a different specificity from that of spontaneous human AKA.

AKA were associated with the presence of subcutaneous nodules in RA $(p=0 \cdot 05)$, but not with Raynaud's phenomenon, Sjögren's syndrome, or HLA-DR4 positivity. Rheumatoid factor (RF) $\stackrel{\unrhd}{\stackrel{一}{\circ}}$ was not associated with AKA either in RA or in RF-positive disease controls.

It has been suggested that defective immunoregulation may be central to the pathogenesis of rheumatoid arthritis. ${ }^{12}$ Several non-organ-specific autoantibodies have been described in RA and in other related connective tissue diseases. ${ }^{3}$ Certain autoantibodies may be more specific for $\mathrm{RA},{ }^{4}$ and we have previously described a possible relationship between rheumatoid factors and autoantibodies to keratin. ${ }^{5}$ Antikeratin antibodies were first described in $\mathrm{RA}^{6}$ but have since been reported in systemic lupus erythematosus (SLE) ${ }^{7}$ systemic sclerosis, ${ }^{689}$ and ankylosing spondylitis. ${ }^{9}$

In this study we have tested for any possible disease specificity of AKA, within a spectrum of connective tissue diseases and miscellaneous conditions reported to be associated with rheumatoid factor or AKA production. We included Sjögren's syndrome ${ }^{10}$, psoriasis, ${ }^{11}$ subacute bacterial endocarditis, ${ }^{12}$ primary myxoedema, ${ }^{13}$ and silicosis. ${ }^{14}$ We also describe AKA in synovial fluid

Accepted for publication 9 January 1985.

Correspondence to Dr P Youinou, Department of Immunology, University Hospital Medical School, F29279 Brest, Cedex, France. and saliva in RA only and note an association between serum AKA and subcutaneous nodules in RA.

\section{Materials and methods}

A total of 2152 disease-associated and control sera 궁 were tested. These included 421 patients with $\frac{D}{O}$ classical or definite $\mathrm{RA}^{15}$ seen at the Brest University Hospital or The Middlesex Hospital, London. $\mathbf{A}_{\sigma}^{N}$ particular note of the presence of Sjögren's syn- $N$ drome, Raynaud's phenomenon and subcutaneous nodules was made in 144 cases of RA. Patients with ${ }^{\omega}$ other diseases were included as controls in the study? (see Tables 1 and 2); all cases of systemic sclerosis, ankylosing spondylitis (AS), and primary Sjögren's syndrome fulfilled the proposed diagnostic criteria ${ }_{-}^{-}$ for the respective diseases. ${ }^{16-19}$ Normal controls included healthy clinical and laboratory staff, medi- $-\vec{\Phi}$ cal students, and residents of two homes for the $\frac{\widetilde{\Phi}}{\mathbb{Q}}$ elderly.

Synovial fluid (SF) was obtained from 58 patients? with active RA, eight patients with other inflamma-尺 
Table 1 Incidence of antikeratin antibodies in serum, synovial fluid, and saliva of patients with rheumatoid arthritis, disease controls and normals

\begin{tabular}{|c|c|c|c|}
\hline \multirow[t]{2}{*}{ Diagnosis } & \multicolumn{3}{|c|}{ No. positive $* /$ No. tested (\%) in: } \\
\hline & Serum & Synovial fluid & Saliva \\
\hline Rheumatoid arthritis & $156 / 421(37 \cdot 1)$ & $28 / 58(48 \cdot 3)$ & $1 / 21+(3 \cdot 2)$ \\
\hline Systemic sclerosis & $2 / 26 \quad(7 \cdot 7)$ & $0 / 1$ & $0 / 7$ \\
\hline Ankylosing spondylitis & $2 / 35 \quad(5 \cdot 7)$ & $0 / 4$ & $0 / 4$ \\
\hline Systemic lupus erythematosus & $(3 \cdot 3)$ & $0 / 3$ & $0 / 6$ \\
\hline Normal controls & $6 / 247 \quad(2 \cdot 4)$ & $0 / 20$ & $0 / 30$ \\
\hline
\end{tabular}

*Serum antikeratin antibodies were screened at $1 / 10$ dilution in PBS, while synovial fluid and saliva AKA were screened neat. †Of these, 12 had a Sjögren's syndrome.

Table 2 Incidence of antikeratin antibodies in other connective tissue diseases and in other diseases associated with rheumatoid factor production

\begin{tabular}{lll}
\hline Diagnosis & $\begin{array}{l}\text { No. } \\
\text { tested }\end{array}$ & $\begin{array}{l}\text { No. } \\
\text { positive (\%) }\end{array}$ \\
\hline Primary myxoedema & 34 & $4(11 \cdot 8)$ \\
Subacute endocarditis & 10 & $1(10 \cdot 0)$ \\
Psoriasis & 69 & $5(7 \cdot 2)$ \\
Alcoholic cirrhosis & 35 & $2(5 \cdot 7)$ \\
Sjögren's syndrome & 52 & $1(1 \cdot 9)$ \\
Silicosis & 12 & 0 \\
Polymyalgia rheumatica & 25 & 0 \\
Reiter's syndrome & 22 & 0 \\
Chronic active hepatitis & 19 & 0 \\
Pernicious anaemia & 14 & 0 \\
Primary biliary cirrhosis & 11 & 0 \\
Periarteritis nodosa & 10 & 0 \\
\hline
\end{tabular}

tory joint diseases, and 20 patients with meniscal tears or osteoarthritis which served as 'noninflammatory' normal controls. Synovial fluid was collected in preservative-free heparin and immediately centrifuged at $400 \mathrm{~g}$ at $4^{\circ} \mathrm{C}$ for $20 \mathrm{~min}$ to remove cellular debris. The supernatant was then treated with hyaluronidase $(150 \mathrm{U} / \mathrm{ml}$, Sigma) for 15 min at $37^{\circ} \mathrm{C}$ and stored in aliquots at $-70^{\circ} \mathrm{C}$ until tested.

Saliva from 21 RA patients, 17 disease controls and 30 normal controls was centrifuged, dialysed against borate-buffered saline $0 \cdot 1 \mathrm{M} \mathrm{pH} 7 \cdot 2$, and stored at $-70^{\circ} \mathrm{C}$ until tested.

\section{ANTIKERATIN ANTIBODY TEST}

Serum antikeratin antibodies were screened at $1 / 10$ dilution in phosphate-buffered saline $0.01 \mathrm{M} \mathrm{pH} \mathrm{7.3}$ by indirect immunofluorescence, on a tissue substrate of the middle third of rat oesophagus as described by Young et al. ${ }^{6}$ Synovial fluid and saliva AKA were screened neat. Rabbit antihuman IgG, isotype-specific (fluorescein isothiocyanate) conjugate was used (Kallestad).

TISS UE TYPING

Lymphocytes from 58 RA patients were tested for DR4 positivity by a microcytotoxicity test ${ }^{20}$ with a panel of antisera from France-Transplant.

\section{OTHER TECHNIQUES}

A rabbit antihuman keratin antiserum was raised as described in detail elsewhere ${ }^{21}$ and used for blocking experiments. Sections of rat oesophagus were incubated with non-immune rabbit serum or rabbit antihuman keratin antiserum for $30 \mathrm{~min}$, washed thoroughly, and then incubated with high titre AKA-positive RA sera.

Seven AKA-positive RA sera were tested by immunofluorescence on sections of rabbit prepuce and lips. A fluoresceinated sheep antirabbit $\mathrm{Ig}$ (Nordic) was used as conjugate for the rabbit antihuman keratin antiserum.

\section{S T A T IS TICS}

The figures quoted below are percentages or geometric means. Data were analysed by the $\chi^{2}$ test, with Yates's correction when required, or by the Mann-Whitney U test.

\section{Results}

Antikeratin antibodies of IgG class were frequently detected in RA sera $(37 \cdot 1 \%)$ and synovial fluid $(48.3 \%)$ but only in $1 / 21$ samples of RA saliva. Both normal and disease control groups showed a low incidence of AKA in serum $(2 \cdot 4-7 \cdot 7 \%)$, and no positives were found in control SF or saliva samples (Table 1). Sera from another 12 diseases associated with spontaneous production of RF also showed a low incidence of AKA.

The titre of AKA in RA sera was significantly greater than disease controls $(p<0.05)$ and normals 
$(\mathrm{p}<0.04)$ (Fig. 1). In a comparison of 58 paired samples of RA serum and SF (Fig. 2) we noted a consistently lower AKA titre in the SF samples.

Statistical analysis of the results from 144 patients with RA whose specific clinical details were available showed an association between AKA positivity and subcutaneous nodules $(\mathrm{p}<0 \cdot 05$, Table 3 ) but no correlation with Sjögren's syndrome or Raynaud's phenomenon. Although there was slight increase in AKA positivity in the 36 DR4-positive cases of RA (44.4\% positive) as against the 22 DR4-negative

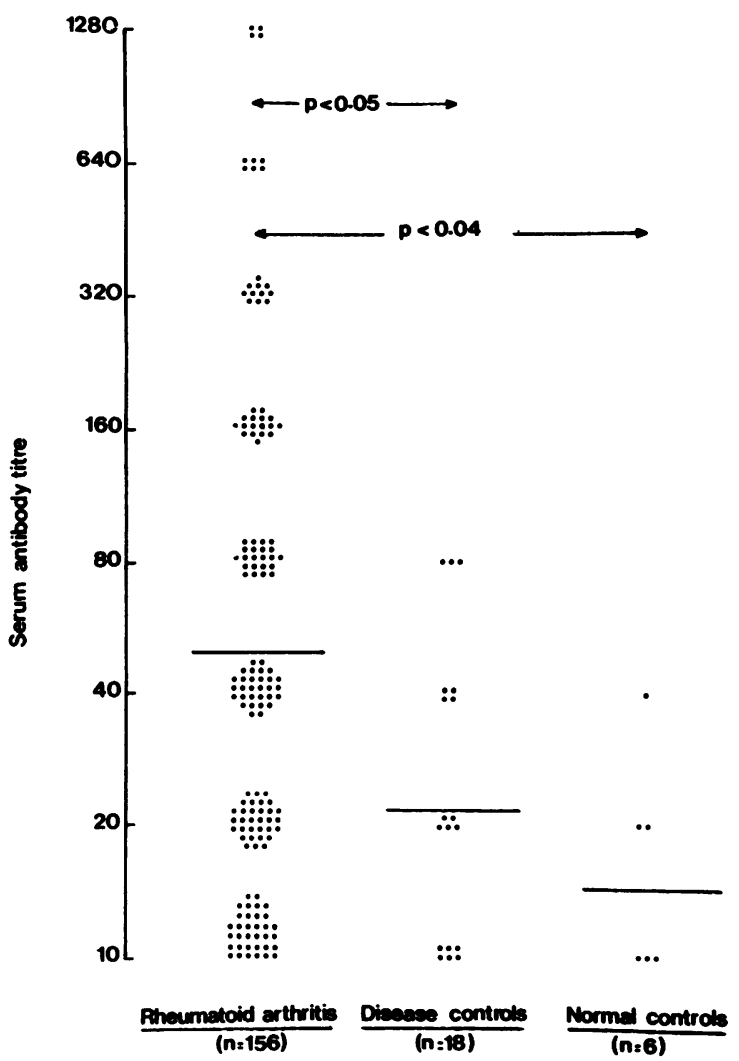

Fig. 1 Titres of serum antikeratin antibodies in rheumatoid arthritis patients, disease controls, and normals.

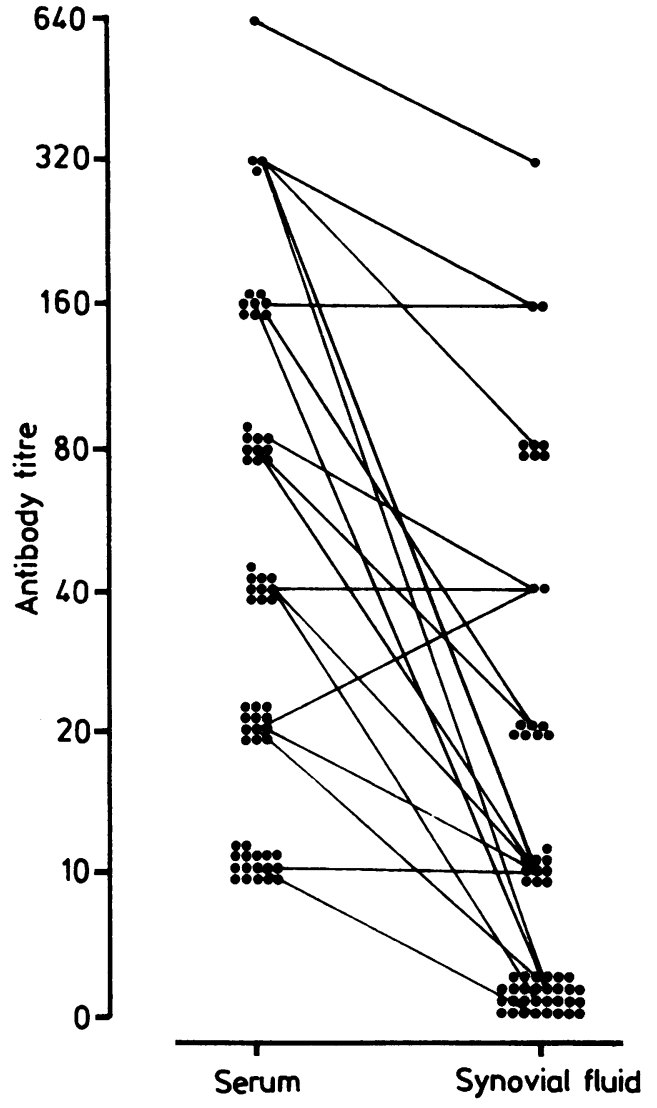

Fig. 2 Titres of antikeratin antibodies in 58 paired samples of rheumatoid arthritis serum and synovial fluid.

group $(27 \cdot 3 \%$ positive) this was not statistically significant.

Further tests on seven AKA positive RA seraß showed binding to stratum corneum of rabbit prepuceo and lips, but we also found four sera which bound to the upper cell layer and four which bound to the? glandular orifices (Thivolet $e t$ al., manuscript in preparation).

When a rabbit antiserum to human keratin was 0 used to define the specificity of naturally occurring

Table 3 Clinical associations of antikeratin antibodies in a study of 144 patients with rheumatoid arthritis

\begin{tabular}{|c|c|c|c|c|c|c|}
\hline \multirow[t]{2}{*}{ Antikeratin antibodies } & \multicolumn{2}{|c|}{ Raynaud's phenomenon } & \multicolumn{2}{|c|}{ Sjögren's syndrome } & \multicolumn{2}{|c|}{ Subcutaneous nodules } \\
\hline & Yes & No & Yes & No & Yes & No \\
\hline Positive (No.) & 9 & 47 & 14 & 41 & $15^{*}$ & 48 \\
\hline Negative (No.) & 15 & 73 & 31 & 58 & 9 & 72 \\
\hline
\end{tabular}




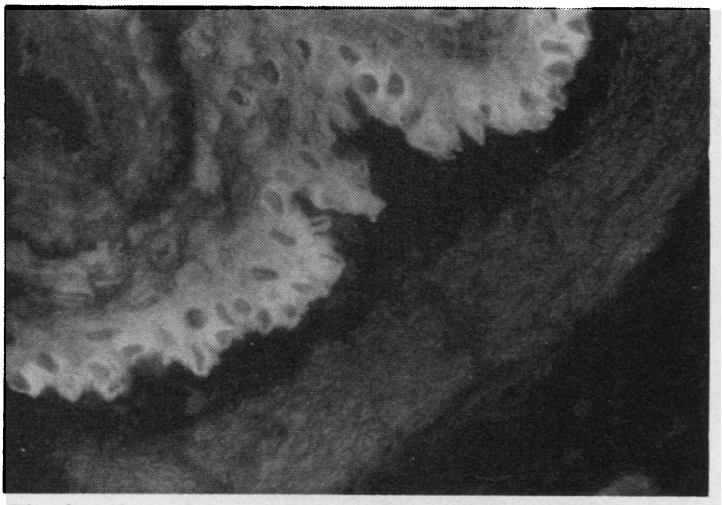

Fig. 3a

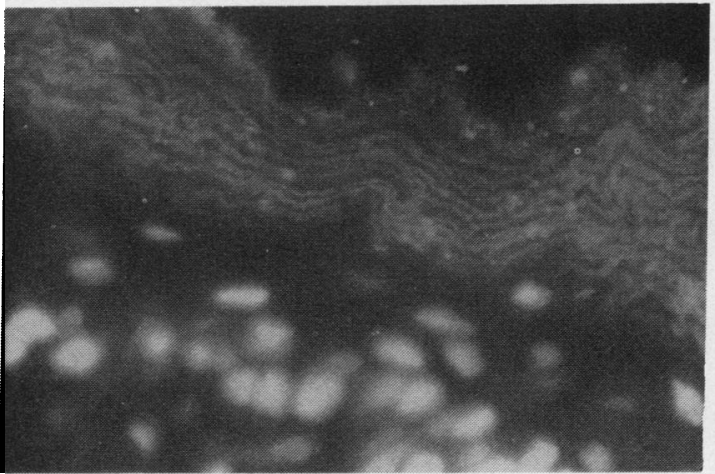

Fig. 3b

Fig. 3 Immunofluorescence pattern obtained on rat oesophagus stained with: (a) rabbit antihuman keratin antiserum; (b) high titre antikeratin antibody positive human $R A$ serum.

human AKA, we found it did not block human AKA activity and instead showed binding to the basal cell layer (Fig. 3a) in contrast with the human sera which found more superficial layers of keratin in the rat oesophagus preparation (Fig. 3b).

\section{Discussion}

In this extensive long-term study we have found serum AKA to be relatively specific for RA. Although it is of low sensitivity at a prevalence of $37 \%$ in RA, we detected AKA in only $3-8 \%$ of other connective tissue diseases. This appears to be lower than some previous reports of AKA in Sjögren's syndrome, $50 \% ;^{8} \mathrm{AS}, 25 \% ;^{9}$ and SLE, $18 \%{ }^{7}$ We included other RF-positive syndromes as disease controls, which also showed a low incidence of AKA, supporting the earlier demonstration that AKA do not have RF activity. ${ }^{6}$ Further indirect support comes from our finding that AKA are not associated with DR4 positivity, unlike the reported association of DR4 with RF-positive RA. ${ }^{22}$ Additional clarification of this question will however be required as Mallya et al. ${ }^{23}$ have recently reported a close association between AKA abundance and RF and anti-ss-DNA antibodies, in a study of 98 patients. They also found an association with Sjögren's syndrome and subcutaneous nodules. This latter finding is confirmed in our survey (Table 3 ).

High titres of AKA were mainly restricted to RA patients and we propose that a titre of $1: 40$ or higher may be helpful in the diagnosis of RA (Fig. 1). In addition we could only detect AKA in synovial fluid from RA patients, and although we did not correct for total Ig content when comparing AKA titres of paired serum and SF samples, our results confirm the report of Quismorio et al. ${ }^{9}$ that AKA are not concentrated in SF. Despite the absence of IgG anti-AKA in our study of RA saliva, it is possible that IgA anti-AKA could be present; IgA rheumatoid factors have been detected in RA and Sjögren's saliva. ${ }^{10}$

Antibodies to rabbit stratum corneum have not previously been described in association with AKA positivity, but further analysis of AKA specificity on a rat substrate showed restriction of (spontaneous) AKA binding (in RA sera) to the more superficial layers, whereas a specific rabbit antihuman keratin antiserum bound only to the basal cell layer (Figs 3a and $b$ ). These two patterns of binding may represent differences in epitopic specificity between the two types of antibody tested, and further studies are in progress.

In conclusion we have found antikeratin antibodies in titres of $1 / 40$ or above to be relatively specific for rheumatoid arthritis in a study of serum and synovial fluid. The significance and the epitopic specificity of these antibodies require further elucidation.

We wish to thank Dr G D Johnson whose advice enabled us to set up the AKA test. The technical expertise of Ms A Baron and Ms S Forest has been greatly appreciated.

\section{References}

1 Roitt I M, Hay F C, Nineham L J, Male D K. Rheumatoid arthritis. In: Lach-Mann P J, Peters D K, eds. Clinical aspects of immunology. Oxford: Blackwell, 1982; 2: 1161-95.

2 Lydyard $\mathrm{P}$ M, Irving W L. Immunological aspects of rheumatoid arthritis. In: Advanced medicine. London: Saunders, 1983: 156-64.

3 Holborow E J. Autoantibodies in rheumatoid arthritis: some new facts. In: Holborow E J, ed. Clinics in immunology and allergy. London, Philadelphia, Toronto: Saunders, 1981; 12738.

4 Youinou P Y, Morrow W J W, Lettin A W F, Lydyard P M, Roitt I M. Specificity of plasma cells in the rheumatoid 
synovium. I. Immunoglobulin class of antiglobulin-producing célls. Scand $J$ Immunol in press.

5 Miossec P, Youinou P, Le Goff P, Moineau M P. Clinical relevance of antikeratin antibodies in rheumatoid arthritis. Clin Rheumatol 1982; 1: 185-9.

6 Young B J J, Mallya R K, Leslie R D G, Clark C J M, Hamblin $\mathrm{T} \mathrm{J}$. Antikeratin antibodies in rheumatoid arthritis. $\mathrm{Br} \mathrm{Med} \mathrm{J}$ 1979; ii: $97-9$.

7 Johnson G D, Carvalho A, Holborow E J, Russell G. Antiperinuclear factor and keratin antibodies in rheumatoid arthritis. Ann Rheum Dis 1981; 40: 263-6.

8 Scott D L, Delamere J P, Jones L J, Walton K W. Significance of laminar antikeratin antibodies to rat oesophagus in rheumatoid arthritis. Ann Rheum Dis 1981; 40: 267-71.

9 Quismorio F P, Kaufman R L, Beardmore T, Mongan E S. Reactivity of serum antibodies to the keratin layer of rat oesophagus in patients with rheumatoid arthritis. Arthritis Rheum 1983; 26: 494-9.

10 Dunne J V, Carson D A, Spiegelberg H L, Alspaugh M A, Vaughan $\mathrm{J} \mathrm{H}$. IgA rheumatoid factor in the sera and saliva of patients with rheumatoid arthritis and Sjögren's syndrome. Ann Rheum Dis 1979; 38: 161-5.

11 Howell F A, Chamberlain M A, Perry R A, Torrigiani G, Roitt I M. IgG antiglobulin levels in patients with psoriatic arthropathy ankylosing spondylitis and gout. Ann Rheum Dis 1972; 31: 129-31.

12 Bartfield $\mathrm{H}$. Distribution of rheumatoid factor activity in non rheumatoid states. Ann NY Acad Sci 1969; 168: 30-40.

13 Scherbaum W A, Youinou P, Le Goff P, Bottazzo G F. Anti-perinuclear and rheumatoid factor in different forms of autoimmune thyroid diseases. Clin Exp Immunol 1984; 55: 516-8.
14 Wagner J C, MacCormick J N. Immunological investigations of coal workers' diseases. $J R$ Coll Physicians Lond 1967; 2: 49-56.

15 Ropes M W, Bennet G A, Cobb S, Jacox R, Jessar R A. Revision of diagnostic criteria for rheumatoid arthritis. Bull Rheum Dis 1958; 9: 175-6.

16 Masi A T, Rodnan G P, Medsger T A Jr, et al. Preliminary criteria for the classification of systemic sclerosis (scleroderma). Arthritis Rheum 1980; 23: 581-90.

17 Bennett P H, Burch T A. New York symposium on population studies in the rheumatic diseases: new diagnostic criteria. Bull Rheum Dis 1967; 17: 453-8.

18 Tan E M, Cohen A F, Fries J F, et al. The 1982 revised criteria for the classification of systemic lupus erythematosus. Arthritis Rheum, 1982; 25: 1271-7.

19 Moutsopoulos H M. Clinical features of Sjögren's syndrome. In: Moutsopoulos H M, moderator. Sjögren's syndrome (sicca syndrome): current issues. Ann Intern Med 1980; 92: 212-26.

20 Terasaki P I, Bernoco D, Park M S, Osturk G, Iwaki Y. Microdroplet testing for HLA-A, -B, -C and -D antigens. Am J Clin Pathol 1978; 69: 103-20.

21 Viac J, Staquet M J, Thivolet J, Goujon C. Experimental production of antibodies against stratum corneum keratin polypeptides. Arch Dermatol Res 1980; 267: 179-88.

22 Dobloug J H, Forre O, Kass E, Thorsby E. HLA antigens and rheumatoid arthritis. Association between HLA-DRw4 positivity and IgM rheumatoid factor production. Arthritis Rheum 1980; 23: 309-12.

23 Mallya R K, Young B J J, Pepys M B, Hamblin T J, Mace B E W, Hamilton E B D. Antikeratin antibodies in rheumatoid arthritis: frequency and correlation with other features of the disease. Clin Exp Immunol 1983; 51: 17-20. 